\title{
MARKETING CAPABILITIES IN THE DIGITAL ENVIRONMENT. CONSEQUENCES ON THE PERFORMANCE OF THE COMPANY
}

\author{
Valentina-Simona Pașcalău \\ Doctoral School of Economics and Business Administration, West University of Timișoara, \\ Timisoara, Romania \\ valentina.pascalau73@e-uvt.ro
}

\begin{abstract}
The purpose of this paper is to identify the effects of marketing capabilities in the digital environment on the company's performance. To test these effects, the data was obtained through a questionnaire-based survey on a sample of 38 companies that have operations in Romania. For the statistical processing of the data in the empirical research, we used the software program SPSS 23, and regarding the achievement of the objectives associated with the present research, the statistical analysis process of the data included several stages. The first stage is the calculation of the relative frequencies for the questions included in the questionnaire that concern aspects related to the firmographic characteristics linked to the investigated sample: the origin of the firm's capital, the number of employees, the turnover, the weight of the turnover realized on the account of legal and physical persons and the economic sector in which they carry out their activity. In the second stage, the reliability of the measurement scales used to deal with the constructs investigated in the present research was tested using the Cronbach coefficient $\alpha$. In order to test the research hypotheses considered in this research, in the next stage, we used the confirmatory factorial analysis, with which we tested the factorial load of each item, and subsequently, we aggregated the respective items. The results suggest that the marketing capabilities in the digital environment have a positive effect on the 3 dimensions of performance analysed in this article (performance of customer relations, performance of the marketing of the company, the financial performance of the company) in an emerging economy.
\end{abstract}

Keywords: marketing capabilities, digital marketing, customer relations, performance.

JEL classification: M31.

\section{Introduction}

The embrace on a wide scale of the digital technologies by consumers and companies alike has led to major changes in the practice of marketing. Increasing the level of consumer knowledge due to access to information and digital transformation of business and exchange processes involves the development of new useful marketing capabilities in the digital environment. Marketing capabilities influence both the sustained competitive advantage of an organization and the intensity of innovation, but however, literature on the role of marketing capabilities in the competitive strategy has been limited.

When we talk about marketing capabilities, we can refer to the strategic theory and practices of marketing through organizational innovation, the sustained competitive advantage of the company or to the development, improvement and validation of entrepreneurship measures. The marketing capabilities of a company are reflected in its ability to differentiate competing products and services and build successful brands, "companies with strong brand names can charge premium prices on foreign markets to improve their capacity as well" (Kotabe et al., 2002: 82). 
Increased digitization and digitalization can lead to significant challenges for organizations facing complex and ever-changing markets that are out of control. The growing presence of digital marketing also raises important questions for marketing management and research. Once the information has been collected by an organization from their clients, the next important task to undertake is to integrate the information.

Information integration requires the assimilation of customer information from all interactions to develop a detailed picture of each customer relationships in the utopia of a "unique customer vision" (Jayachandran, 2005). Previous CRM (Customer Relationships Management) systems have managed to integrate online data from websites and e-mail interactions. There is no set format for importing social data; rather, its power comes from its qualitative and profound nature.

To counter this problem, the software industry is developing new -tools to make it possible to integrate data from different social media sources into a format that can be quantified and generalized to some extent. For digital marketers, there are three major challenges, namely: (1) the ability to generate and leverage customers' deep knowledge, (2) brand management and reputation in a marketing environment where social media plays an important role and (3) assessing the effectiveness of digital marketing.

The use of the internet continues to explode worldwide, becoming an increasingly important digital source of competitive advantage in B2C (Business to Customer) and B2B (Business to Business) marketing. Much attention has been focused on the extraordinary opportunities of digital marketing and the focus on the real challenges for companies facing digitalization. (Leeflangab et al, 2014).

The widespread adoption of digital technologies by consumers and companies has led to major changes in the marketing practice. Increasing the level of consumer knowledge due to access to information and the digital transformation of business processes and exchange processes require the development of new useful marketing capabilities in the digital environment.

The purpose of this paper is to develop a conceptual model for researching the consequences of marketing capabilities in the digital environment and on the company's performance.

\section{Literature review}

In the last two decades, we have witnessed a real explosion of marketing research regarding the impact of the Internet and related technologies on consumers and how markets work. In the digital environment, there are four key interactions: consumer-firm interactions, firmconsumer interactions, consumer-consumer interactions and firm-firm interactions (Yadav, 2014). The research of consumer-firm interactions focuses on the behavior of consumers in the context of interaction with companies in the digital environment. The research of the company-consumer interactions focuses on the strategies and tactics of the companies that interact with the consumers in the digital environment. The research of consumer-consumer interactions consists of analyzing the behavior of consumers interacting with other consumers in the digital environment. The research of the company-company interactions concerns the strategies and tactics of a company in the context of the interaction with other companies in the digital environment.

Marketing capabilities are defined as a unique package of skills and resources that facilitate business execution, and marketing processes are the ones that ultimately contribute to a lasting competitive advantage and a superior performance (Day, 1994)

Marketing capabilities represent what the organization can do by using its resources in an integrated way. The literature identifies certain specific marketing capabilities used to transform resources into valuable outcomes based on the classic marketing mix (Vorhies 
and Morgan, 2003), and to orchestrate marketing capabilities, resource inputs that involve managing market information, as well as those of developing and executing the marketing strategy.

The development of marketing capabilities in the digital environment is carried out in order to increase the competitiveness and the performance of the companies. The capabilities theory identifies as the source of sustaining the competitive position the distinctive and hardto-copy resources that the company has developed over time.

The marketing capabilities can be considered as complex sets of knowledge and skills accumulated, exercised through organizational processes, which allow organizations to coordinate their activities and can influence a profit growth, capabilities can be complementary when the return to one capability is affected by the presence of another (Milgrom and Roberts, 1990; Moorman and Slotegraaf, 1999)

In terms of customer engagement, as the main marketing capability, organizations are under pressure to deliver superior customer value, which in turn enhances customer loyalty to the organization and its product offerings (Moorman and Rust, 1999).

According to Day (2011, pp.183-185), marketing capabilities are defined as integration processes designed to apply the collective knowledge, skills and resources to the business market needs, allowing the organization to add value to its goods and services and can respond to competitive demands.

Marketing capabilities are developed by orienting the employees of the firm who repeatedly apply their knowledge to solve the marketing problems of the organization (Day, 1994; Grant, 1991, 1996).

\section{Research methodology}

\subsection{Data collection}

We used single informant self-reported data collected from a sample 38 companies from Romania; an invitation was sent by email to the marketing managers of these firms, together with a cover letter that explained the purpose and confidentiality policy of the survey, inviting them to complete the questionnaire online.

First, we asked respondents questions related to the firmographic characteristics concerning the investigated sample: the origin of the firm's capital, the number of employees, the turnover, the weight of the turnover realized on the account of legal and natural persons and the economic sector in which they carry out their activity.

The sample includes firms from various sectors: IT\&C (24.95\%), trading (30.02\%), services $(28.55 \%)$, industry goods (13.35\%) and other domains (3.13\%). The small companies with less than 50 employees count for $73.50 \%$, medium sized firms represent $13.25 \%$, and the remaining $13.25 \%$ are large companies. Companies with turnover under 500.000 Euros represents $40.96 \%$, companies with turnover between 500.000 and 2 million count for $7.23 \%$, and $6.02 \%$ with a turnover over 2 millions. The specific item indicators and questions for each survey measure are contained in the Appendix.

\subsection{Measuring reliability and validity}

After testing the reliability of the scales used, the suitability of the factorial analysis was tested in the next stage of the statistical analysis of the data. The adequacy of the factorial analysis was tested using the KMO coefficient and Bartlett's test. This analysis was performed for each construct, resulting in the adequacy to perform the factorial analysis for each construct (the KMO coefficient value was greater than 0.5 for each construct and the significance level $p$ for each the Bartlett's test was less than 0.05 ). 
Given that there is suitability for conducting factorial analysis for each construct, one of the forms of factorial analysis, confirmatory factorial analysis (CFA), has been developed. Through the CFA were eliminated from the measurement scales used to deal with the investigated constructs the items that had lower factor loadings as a value of the minimum admitted limit of 0.5 . After this step, the Cronbach coefficient $\alpha$ was recalculated for the constructs for which the items were removed. In the present research, it was only in the case of two constructions that the items were eliminated after the CFA. These constructions are customer satisfaction and commitment.

Also, with the help of the CFA the aggregation of items (observable variables) in dimensions and dimensions in constructions was achieved. This step was necessary to carry out the testing of the research hypotheses that presupposes the existence of links between the investigated constructs.

After the CFA was performed, the validity of the investigated constructs in two forms was tested, convergent and validity. Testing the two forms of validity was performed using the Pearson correlation coefficient and it turned out that all constructs included in the conceptual model are valid.

\subsection{Hypothesis development}

The proposed model represents a development of the model of Morgan, Vorhies and Mason (2009), which are based on the following hypotheses:

a) the orientation towards the market of a company is positively associated with its business performance.

b) the marketing capabilities of a company are positively associated with its business performance.

c) the interaction between the company orientation towards the market and the marketing capacities is positively associated with the activity of the performance company.

The results of the hypotheses formulated by the authors show that in the two subjective performance models, the path coefficients support both hypothesis, 2 and 3 , but no support is found for hypothesis 1 because the path coefficient is not significant in either the main effects or the interaction model.

Their study suggests future research paths that may hold particular promise given the value creating potential of marketing capabilities revealed in the study, it is important to know how such capabilities are developed and how they help to build as well as deploy a firm's performance knowledge resource.

On the basis of the previous research, we have formulated the following hypothesis based on which we structured the conceptual model of the research on the company's strategic orientations consequences on the marketing capabilities in the digital environment and on the company's performance.

H1: The marketing capabilities in the digital environment exert a direct and positive influence on the customer relationships performance.

H2: The marketing capabilities in the digital environment exert a direct and positive influence on the marketing performances of the company.

H3: The marketing capabilities in the digital environment exert a direct and positive influence on the financial performance of the company

For an organization, it is important to develop the most critical capabilities to be successful, by applying specific strategies, and this should be reflected in the financial performance. Customer relationship performance was adapted from scales used by Trainor in 2011 . Respondents were asked to answer the following question: "In relation to the objectives set, how do you assess the evolution of your company's performance over the last 3 years? (1much weaker; 7-much better)": (1) customer satisfaction, and (2) customer loyalty. All Likert 
scale items were anchored at 1 (Worse) to 7 (Better). The reliability was found to be $\alpha=0.886$ for these two customer items.

Marketing performance of the company was adapted from scales used by Morgan, Vorhies, Mason (2009). Respondents were asked to answer the following question: "In relation to the objectives set, how do you assess the evolution of your company's performance over the last 3 years? (1-much weaker; 7-much better)": (1) allocating marketing resources effectively implementation; (2) organizing to deliver marketing programs effectively capabilities; (3) translating marketing strategies into action; (4) executing marketing strategies quickly. All Likert scale items were anchored at 1 (Worse) to 7 (Better). The reliability was found to be $\alpha=0.802$ for these marketing performance items.

Financial performance of the company was adapted from scales used by Vorhies, Harker (2000). Respondents were asked to answer the following: "In relation to the objectives set, how do you assess the evolution of your company's performance over the last 3 years? (1much weaker; 7-much better)": (1) business unit profitability; (2) return on investment (ROI); (3) return on sales (ROS). All Likert scale items were anchored at 1 (Worse) to 7 (Better). The reliability was found to be $\alpha=0.724$ for these financial performance items.

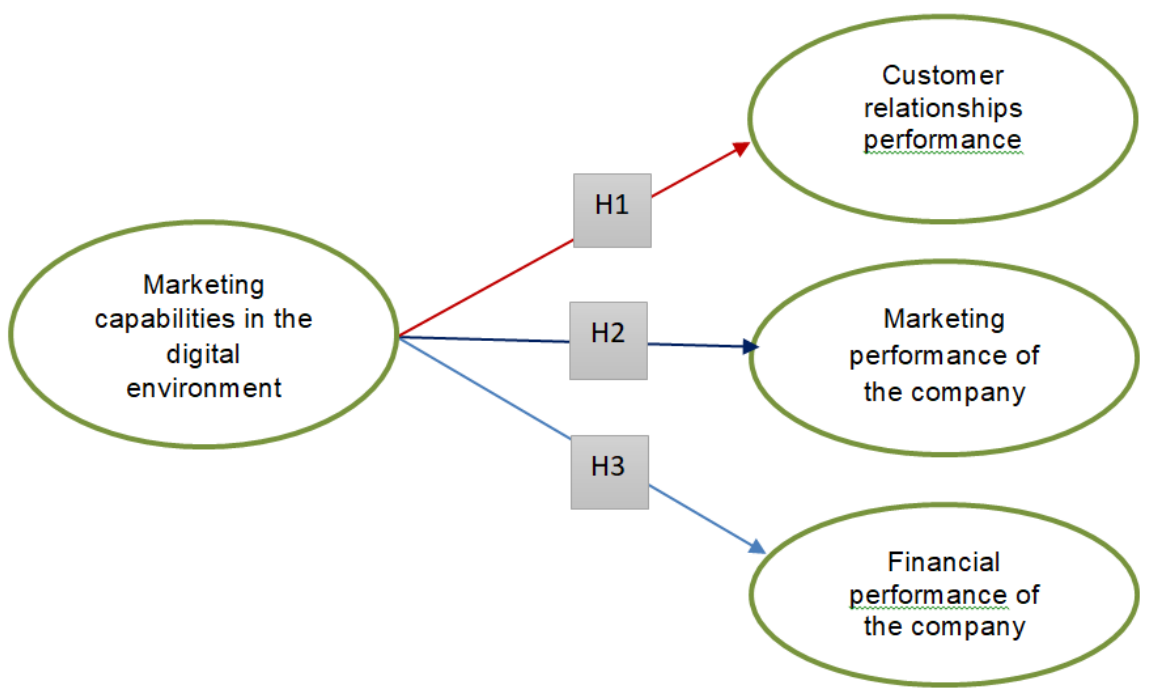

Figure 1. Structural model

\subsection{Results of the hypotheses testing}

Determining the influence of marketing capabilities on customer relationships performance, marketing performance of the company and financial performance of the company is a matter of great interest for researchers and managers alike.

Testing the research hypotheses is the main objective of the data analysis process and the entire research. To test these hypotheses, in the earlier stages of the data analysis plan, the variables observed in the sample were aggregated into constructs (latent variables).

The constructs resulting from the aggregation of the observed variables were correlated according to the research hypotheses formulated.

In order to test the research hypotheses considered in this research, we performed the confirmatory factorial analysis, with which we tested the factorial load of each item that was selected to make one of the 4 constructs mentioned in the theory part. Subsequently, we added the respective items, so that we remain with 11 variables, which is the sum of the items of the initial construction. 
In the last stage of the statistical analysis process, the hypotheses of the proposed conceptual model were tested using simple linear regression. During this stage we introduced new variables, obtained from the aggregation of items, as exogenous variables or as result variables.

The table below shows the measurement scales used to measure each construct included in the conceptual model.

Table 1: The measurement scales

\begin{tabular}{|c|c|}
\hline $\begin{array}{c}\text { Marketing capabilities } \\
\text { (Vorhies and Harker, 2000) }\end{array}$ & $\begin{array}{l}\text { Our marketing research abilities help us find more new } \\
\text { customers than do our competitors } \\
\text { Market research skills help us develop effective marketing } \\
\text { programs } \\
\text { We use our marketing research information more } \\
\text { effectively than our competition uses their own marketing } \\
\text { research information } \\
\text { Our marketing research expertise helps us develop better } \\
\text { marketing programs than our competition }\end{array}$ \\
\hline $\begin{array}{c}\text { Customer relationships } \\
\text { performance }\end{array}$ & Customer satisfaction \\
\hline (Trainor, 2011) & Customer loyalty \\
\hline $\begin{array}{c}\text { Marketing performance of } \\
\text { the company } \\
\text { (Morgan, Vorhies, Mason, } \\
\text { 2009) }\end{array}$ & $\begin{array}{l}\text { Allocating marketing resources effectively implementation } \\
\text { Organizing to deliver marketing programs effectively } \\
\text { capabilities } \\
\text { Translating marketing strategies into action } \\
\text { Executing marketing strategies quickly }\end{array}$ \\
\hline $\begin{array}{l}\text { Financial performance of } \\
\text { the company } \\
\text { (Vorhies and Harker, 2000) }\end{array}$ & $\begin{array}{l}\text { Business unit profitability } \\
\text { Return on investment (ROI) } \\
\text { Return on sales (ROS) }\end{array}$ \\
\hline
\end{tabular}

Through the empirical research conducted in this study, we set out to test the explanatory power of the conceptual model based on the existing models in the specialized literature. For the entry into operation of the constructs included in the conceptual model of the research, we used scales proposed and validated by other researchers in the field of marketing. These scales were adapted to the context of the present research. The measurement scales used to measure the investigated constructs were tested in terms of their reliability. Their reliability was tested using the Cronbach coefficient $\alpha$. Following the reliability test it was found that for all scales used the Cronbach coefficient $\alpha$ value was higher than 0.700 . Therefore, we can say that the scales used in the presented research to measure the investigated constructs are reliable.

In the first stage of analysis of these constructs, the reliability of the constructs was tested, resulting in a Cronbach $\alpha$ value indicating that the scale is reliable.

Testing the research hypotheses is the main objective of the data analysis process and the entire research. To test these hypotheses, in the earlier stages of the data analysis plan, the variables observed in the sample were aggregated into constructs (latent variables).

In the following paragraphs we present the results obtained for the test of the research hypotheses using a simple linear regression.

The results agree with those obtained by other researchers in the field of marketing and are presented in the following. These results were obtained after testing the research hypotheses by using a linear regression. 
This chapter highlights the results obtained as a result of testing the reliability of the measurement scales, of the confirmatory factorial analysis and as a result of testing the research hypotheses included in the conceptual model.

Within this subchapter the results obtained as a result of testing the research hypotheses using simple linear regression are presented.

The research hypothesis no.1 aims to analyze the direct effect that customer relationships performance has on marketing capabilities.

The research hypothesis no.2 aims to analyze the direct effect of marketing performances of the company on marketing capabilities.

The research hypothesis no.3 aims to analyze the direct effect that the profitability has on marketing capabilities.

Table 2 presents the results of testing this hypothesis and shows us that hypothesis 1 is confirmed because the two variables are correlated with each other, a fact revealed by the value of the correlation coefficient $(R=0.834)$, and the connection between them is positive and significant from statistically $(\beta=0.834, p=0.000)$.

We can also state that $69.60 \%\left(R^{2}=0.696\right)$ of the variation of the variable of customer relationships performance is generated by the variation of the variable marketing capabilities.

Hypothesis 2 is confirmed because the two variables are correlated with each other, a fact revealed by the value of the correlation coefficient $(R=0.632)$, and the connection between them is statistically significant and positive $(\beta=0.632, p=0.000)$.

We can say that $39.90 \%\left(R^{2}=0.399\right)$ of the variation of the marketing performance variable of the company is generated by the variation of the marketing capabilities variable.

Also, hypothesis 3 is confirmed because the two variables are correlated with each other, a fact revealed by the value of the correlation coefficient $(R=0.633)$, and the connection between them is positive and statistically significant $(\beta=0.633, p=0.000)$.

Thus, we can say that $40 \%\left(R^{2}=0.400\right)$ of the variation of the variable financial performance of the company is generated by the variation of the variable marketing capabilities.

Table 2: The results

\begin{tabular}{|c|c|c|c|c|c|c|}
\hline $\begin{array}{c}\text { Independent } \\
\text { variable }\end{array}$ & $\begin{array}{c}\text { The } \\
\text { dependent } \\
\text { variable }\end{array}$ & $\begin{array}{c}\text { Correlati } \\
\text { on } \\
\text { coefficie } \\
\text { nt (R) }\end{array}$ & $\begin{array}{c}\text { Coefficient of } \\
\text { determination } \\
\left(\boldsymbol{R}^{2}\right)\end{array}$ & $\begin{array}{c}\text { The } \\
\text { standardized } \\
\text { coefficient } \\
\text { of the } \\
\text { regression } \\
\text { function }(\boldsymbol{\beta})\end{array}$ & $\begin{array}{c}\text { Signifi } \\
\text { cance } \\
\text { level } \\
\mathbf{( p )}\end{array}$ & $\mathbf{t}$-score \\
\hline $\begin{array}{c}\text { Marketing } \\
\text { capabilities }\end{array}$ & $\begin{array}{c}\text { Customer } \\
\text { relationships } \\
\text { performance } \\
\begin{array}{c}\text { Marketing } \\
\text { performance } \\
\text { of the } \\
\text { company }\end{array}\end{array}$ & .834 & .696 & .834 & .000 & 9.084 \\
& $\begin{array}{c}\text { Financial } \\
\text { performance } \\
\text { of the } \\
\text { company }\end{array}$ & .632 & .399 & .632 & .000 & 4.887 \\
\hline
\end{tabular}




\section{Conclusions}

In this empirical study, we aimed, as a main objective, to test the validity of the links between the different constructs included in the conceptual model of the research. The links between the constructs are presented in this empirical study in the form of research hypotheses. The validity of these research hypotheses was tested by using linear regressions.

All the hypotheses are confirmed; therefore, the variables are correlated with each other, they are relevant in terms of the correlation coefficient $(R)$, and the links between them are positive and statistically significant $(\beta$, sig $\leq 0.05)$.

Our results showed that marketing capabilities have a positive effect on the three dimensions of performance (customer relationships performance, company marketing performance, financial performance of the company). Therefore, managers should focus on customer relationships and customer's loyalty, allocating marketing resources for the effective implementation and collecting of information about marketing research, more effectively than their competition, by using their own marketing research information to record the profitability of the business unit. It's important then that firms respond and adapt to external changes through adaptive mechanisms proposed by prior research and organizational structural factors under which marketing capabilities affect firm performance. If managers lean toward a more analytical understanding of marketing capabilities and enhance the shared understanding of the firm capability set, firms could build relational advantages that allow for greater flexibility and a larger share of customer revenue.

Hence, marketing capability plays an important role in the configuration of customer relationships that together build competitiveness.

Finally, we conclude that our constructs have high reliability and have internal consistency.

\section{References}

Day, G. S., 1994. The capabilities of market-driven organizations, Journal of Marketing, 58 (4), pp. 37-52.

Day, G.S., 2011. Closing the marketing Capabilities Gap, Journal of Marketing, 75, pp.183195.

Leeflangab, P.S.H., Verhoefa, P.C, Dahlströmc, P. and Freundtc, T., 2014. Challenges and solutions for marketing in a digital era, European Management Journal, 32, pp. 1-12.

Grant, R. M. (1991), The Resource-Based Theory of Competitive Advantage: Implications for Strategy formulation, California Management Review, 33 (2), pp. 114-135.

Grant, R.M. 1996. Prospering in dynamically-competitive environments, organisational capability as knowledge integration, Organizational Science, 7 (4), pp. 375-387.

Jayachandran, S., 2005. The Role of Relation Information Processes and Technology Use in Customer Relationships Management, Journal of Marketing, 69 (4), pp. 177-192.

Kotabe, M. Srinivasan, S.S., Aulakh, P.S., 2002, Multinationality and Firm Performance: The Moderating Role of R\&D and Marketing Capabilities, Journal of International Business Studies, 33 (1), pp. 79-97.

Milgrom, P. and Roberts, J., 1990. The economics of modern manufacturing: Technology, strategy, and organization, American Economic Review, 80 (3), pp. 511-528.

Moorman, C., and Slotegraaf, R.J.,1999. The contingency value of complementary capabilities in product development, Journal of Marketing Research, 36 (2), pp. 239-257.

Moorman, C. and Rust, R. T., 1999. The Role of Marketing, Journal of Marketing, 63, pp. 180-197.

Morgan, N.A., Vorhies, D.W. and Mason, C.H., 2009. Market Orientation, Marketing Capabilities, and Firm Performance, Strategic Management Journal, 30 (8), pp. 909-920. 
Trainor, K.J. Rapp, A., Beitelspacher, L.S., Schillewaert, N., 2011. Integrating information technology and marketing: An examination of the drivers and outcomes of e-Marketing capability, Industrial Marketing Management, 40 (1), pp. 162-174.

Vorhies, D. W. and Harker, M., 2000. The Capabilities and Performance Advantages of Market-Driven Firms: An Empirical Investigation, Australian Journal of Management, 25 (2), pp. $145-171$.

Vorhies, D. W. and Morgan, N. A., 2003. A Configuration Theory Assessment of Marketing Organization Fit with Business Strategy and Its Relationships with Marketing Performance, Journal of Marketing, 67 (1), pp. 100-115.

Yadav, M. S. and Pavlou, P. A. 2014. Marketing in Computer-Mediated Environments: Research Synthesis and New Directions, Journal of Marketing, 78 (1), pp. 20-40.

Harvard Business Review (2010), https://hbr.org/2010

Marketing Week (2011), https://www.marketingweek.com/2011

\section{Bio-note}

Valentina-Simona Pașcalău is a PhD student at the West University of Timisoara, Faculty of Economics and Business Administration, Area of study: Marketing. The author's areas of interest in research include Marketing, Digital Marketing and Business Communication and Negotiation. In these areas she attended training programs based on university studies, as well as conducted an individual scientific research program. She published and presented papers in this field in scientific journals and conference proceedings. 


\section{Appendix 1. QUESTIONNAIRE}

1. What is the main field of activity of your company?

2. Company's capital origin:
a) Romanian
b) Foreign
c) Mixed

3. Number of employees (at the end of 2019):
a) 0 - 50 persons
b) $51-100$ persons
c) over 100 persons

4. Turnover of your company (at the end of 2019):
a) below 500,000 Euro
b) $500.001-2.000 .000$ Euro
c) over 2 million Euro

5. In which economic sector your business mainly operates?
a) Industry goods
b) Trading
c) Services
d) IT\&C
e) Other

6. Please specify to what extent you agree with the following statements regarding the capabilities of digital marketing within your company (1- Total disagreement; 7 - Total agree).

\begin{tabular}{|l|c|c|c|c|c|c|c|}
\hline $\begin{array}{l}\text { Our marketing research abilities help us find more } \\
\text { new customers than do our competitors }\end{array}$ & 1 & 2 & 3 & 4 & 5 & 6 & 7 \\
\hline $\begin{array}{l}\text { Market research skills help us develop effective } \\
\text { marketing programs }\end{array}$ & 1 & 2 & 3 & 4 & 5 & 6 & 7 \\
\hline $\begin{array}{l}\text { We use our marketing research information more } \\
\text { effectively than our competition uses their own } \\
\text { marketing research information }\end{array}$ & 1 & 2 & 3 & 4 & 5 & 6 & 7 \\
\hline $\begin{array}{l}\text { Our marketing research expertise helps us } \\
\text { develop better marketing programs than our } \\
\text { competition }\end{array}$ & 1 & 2 & 3 & 4 & 5 & 6 & 7 \\
\hline
\end{tabular}

7. In relation to the objectives set, how do you assess the evolution of your company's performance over the last 3 years? (1-much weaker; 7 -much better):

\begin{tabular}{|l|l|l|l|l|l|l|l|}
\hline Customer satisfaction & 1 & 2 & 3 & 4 & 5 & 6 & 7 \\
\hline Customer loyalty & 1 & 2 & 3 & 4 & 5 & 6 & 7 \\
\hline Efficient allocation of marketing resources & 1 & 2 & 3 & 4 & 5 & 6 & 7 \\
\hline Organization for efficient delivery of marketing programs & 1 & 2 & 3 & 4 & 5 & 6 & 7 \\
\hline Translation marketing strategies & 1 & 2 & 3 & 4 & 5 & 6 & 7 \\
\hline Fast execution of marketing strategies & 1 & 2 & 3 & 4 & 5 & 6 & 7 \\
\hline Business unit profitability & 1 & 2 & 3 & 4 & 5 & 6 & 7 \\
\hline Return on investment (ROI) & 1 & 2 & 3 & 4 & 5 & 6 & 7 \\
\hline Return on sales (ROS) & 1 & 2 & 3 & 4 & 5 & 6 & 7 \\
\hline
\end{tabular}

8. Your position within the company: 